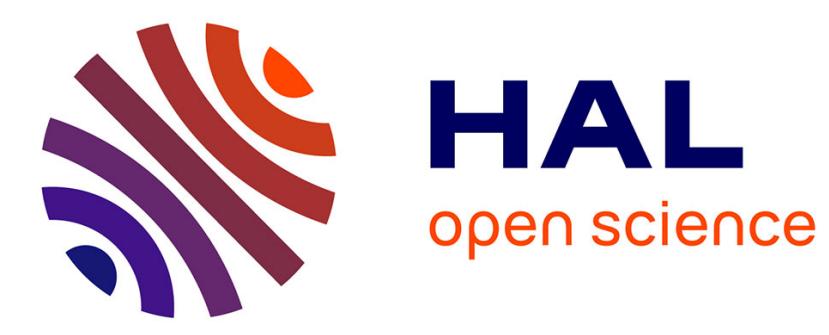

\title{
Robust $H \_2$ observer design for actuator degradation: Application to suspension system
}

\author{
Manh-Hung Do, Damien Koenig, Didier Theilliol
}

\section{To cite this version:}

Manh-Hung Do, Damien Koenig, Didier Theilliol. Robust $H \_2$ observer design for actuator degradation: Application to suspension system. SysTol 2019 - 4th International Conference on Control and Fault-Tolerant Systems, Sep 2019, Casablanca, Morocco. 10.1109/SYSTOL.2019.8864738 . hal02173099

\section{HAL Id: hal-02173099 \\ https://hal.science/hal-02173099}

Submitted on 4 Jul 2019

HAL is a multi-disciplinary open access archive for the deposit and dissemination of scientific research documents, whether they are published or not. The documents may come from teaching and research institutions in France or abroad, or from public or private research centers.
L'archive ouverte pluridisciplinaire HAL, est destinée au dépôt et à la diffusion de documents scientifiques de niveau recherche, publiés ou non, émanant des établissements d'enseignement et de recherche français ou étrangers, des laboratoires publics ou privés. 


\title{
Robust $\mathscr{H}_{2}$ observer design for actuator degradation: Application to suspension system.
}

\author{
Manh-Hung Do, Damien Koenig, and Didier Theilliol
}

\begin{abstract}
The main contribution of paper is a robust $\mathscr{H}_{2}$ observer design to estimate the actuator degradation under the influence of disturbances and parametric uncertainty. In this design, the observer conception, base on the $\mathscr{H}_{2}$ frequencyshaping filter and theorem of Parseval, allows estimating the polynomial form of degradation while coping with system uncertainty. Moreover, the usage of proposed method also relax the condition for unknown input (UI) observer or the minmax optimization in linear matrix inequality (LMI) for the disturbance impact attenuation, which facilitates observer design for engineers. Finally, an application to suspension system is presented to illustrate the performance of the proposed method.

Index Terms-Actuator degradation, Health maintenance, Observer design, Linear Time Invariant (LTI) System, Frequency-shaping.
\end{abstract}

\section{INTRODUCTION}

For the sake of ensuring the long-term normal behavior of a system, the health maintenance has played an important role in both research and industry [1] as it allows not only predicting the remaining usefull life but also preventing the failure that result in serious accidents for users. Thanks to work of [2] and [3], the degradation of components during the system operation can be presented as a polynomial of operating cycle, which grows through its time life and the frequency of exogenous disturbance. For the suspension system, some studies such as [4] also gave the similar experimental results for behavior of damping coefficient or the spring stiffness under the influence of road profile. However, the identification for polynomial coefficient requires numerous data to obtain acceptable estimation result [5], which was not effective for a real-time estimation and in case that the parametric uncertainty exists.

Besides, due to the fact that the degradation also generated the system malfunctions, it can be considered as an fault manipulating state or output behavior. Therefore, numerous methods in fault diagnosis and estimation can be applied to deal with the uncertainty and disturbance. In term of fault estimation, authors in [6] has introduced the polynomial fault where proportional multiple-integral observer was implemented; but this polynomial estimation could not illustrate the correlation between the frequency

Manh-Hung Do and Damien Koenig are with Univ. Grenoble Alpes, CNRS, Grenoble INP*, GIPSA-lab, 38000 Grenoble, France. manh-hung.dodgipsa-lab.grenoble-inp.fr and damien.koenig@gipsa-lab.grenoble-inp. fr

Didier Theilliol is with University of Lorraine, CRAN, UMR 7039, Campus Sciences, B.P.70239, 54506 Vandoeuvre-les-Nancy Cedex, France. didier.theilliolduniv-lorraine.fr

* Institute of Engineering Univ. Grenoble Alpes.

This work is supported by European project 15016 EMPHYSIS. of perturbation and the fault itself. Nevertheless, the decoupling condition for unknown input (UI) observer was also restrictive for application. In work of [7], authors have developed a fast estimation method for suspension system by using the $\mathscr{H}_{\infty}$ synthesis. However, the fault derivative needs to be bounded and the estimation error converges only to a nonzero-bounded region, which could not describe the time-growing development of degradation. Furthermore, the min-max $\mathscr{H}_{\infty}$ synthesis does not always give an optimal optimization of disturbance impact on fault estimation error, which is mainly dependent of perturbation characteristics. To deal with the uncertainty, [8] and [9] have presented a robust interval observer where uncertainty is modelled in a deterministic bounded context and its effect to estimation error is minimized by $\mathscr{H}_{\infty}$ synthesis; however, this method only allows determining the varying zone of fault but not its real value. In [10], the parametric uncertainty of vehicle suspension is also considered as a disturbance and fault can be estimated by the implementation of $\mathscr{H}_{\infty}$ proportionalintegral (PI) observer. Moreover, to improve the disturbance attenuation, authors in [11] also proposed un robust $\mathscr{H}_{\infty}$ PI observer, where the robustness against parametric uncertainty has been relaxed in LMI optimization by using the majoration lemma. Although the 2 above works for suspension have proven its performance, the assumption of slow-varying make it difficult to apply for an actuator degradation.

Therefore, author's method is proposed to overcome above weaknesses with the following contributions:

- A new form for polynomial fault which consider the disturbance effect on its coefficients.

- An alternative method to attenuating the disturbance impact on estimation error, which loosens up the existing constraints in UI observer or LMI optimization problem. That promotes a robust observer design against system uncertainty which is based on frequency-shaping filter and majoration lemma.

An application of vehicle suspension model is also illustrated in this study. In which, the proposed observer promotes a robust estimation of actuator degradation while dealing with the influence of disturbance and uncertainty in the spring stiffness.

The paper is organized as follows. Firstly, the system representation and paper methodology are presented in Section 2. Next, section 3 demonstrates in details the robust observer design for the degradation estimation. Then, an application to the semi-active suspension with the corresponding frequency analysis is then illustrated in Section 
4 to demonstrate the performance of the proposed method. Finally, the conclusion with future work is presented in Section 5.

Notations: $\mathbb{R}^{n}$ represents the $\mathrm{n}$-dimensional Euclidean space; $X^{T}$ is the transpose of the matrix $\mathrm{X} ; 0$ and I denote respectively zeros and identity matrix with appropriate dimensions; the symbol $(*)$ denotes the transposed block in the symmetric position; $X^{\dagger}$ is the pseudo-inverse matrix of $\mathrm{X}$ which satisfies that $X X^{\dagger} X=X ; f^{(s)}$ is the $s^{\text {th }}$ derivative of function $f$; the symbol $(*)$ denotes the transposed block in the symmetric position; $h_{(x)}^{*}=h_{(-x)}^{T}$ is the complex conjugate transpose of signal $h_{(x)}$; and we denote $H e\{A\}=A+A^{T}$.

\section{REFERENCES}

[1] R. Kothamasu, S. H. Huang, and W. H. VerDuin, "System health monitoring and prognosticsa review of current paradigms and practices," The International Journal of Advanced Manufacturing Technology, vol. 28, no. 9-10, pp. 1012-1024, 2006.

[2] J. Luo, K. R. Pattipati, L. Qiao, and S. Chigusa, "Model-based prognostic techniques applied to a suspension system," IEEE Transactions on Systems, Man, and Cybernetics-Part A: Systems and Humans, vol. 38, no. 5, pp. 1156-1168, 2008.

[3] A. Abou Jaoude, "Analytic and linear prognostic model for a vehicle suspension system subject to fatigue," Systems Science \& Control Engineering, vol. 3, no. 1, pp. 81-98, 2015.

[4] C. Suciu and K. Yaguchi, "Endurance tests on a colloidal damper destined to vehicle suspension," Experimental mechanics, vol. 49, no. 3, p. 383, 2009.

[5] N.-H. Kim, D. An, and J.-H. Choi, "Prognostics and health management of engineering systems," Switzerland: Springer International Publishing, 2017.

[6] D. Koenig, "Unknown input proportional multiple-integral observer design for linear descriptor systems: application to state and fault estimation," IEEE Transactions on Automatic control, vol. 50, no. 2, pp. 212-217, 2005.

[7] M. Q. Nguyen, O. Sename, and L. Dugard, "Comparison of observer approaches for actuator fault estimation in semi-active suspension systems," in Control and Fault-Tolerant Systems (SysTol), 2016 3rd Conference on. IEEE, 2016, pp. 227-232.

[8] C. M. García, V. Puig, C. Astorga-Zaragoza, and G. Osorio-Gordillo, "Robust fault estimation based on interval takagi-sugeno unknown input observer," IFAC-PapersOnLine, vol. 51, no. 24, pp. 508-514, 2018.

[9] B. Mrugalska, "A bounded-error approach to actuator fault diagnosis and remaining useful life prognosis of takagi-sugeno fuzzy systems," ISA transactions, vol. 80, pp. 257-266, 2018.

[10] M.-H. Do, D. Koenig, and D. Theilliol, "Robust $h_{\infty}$ proportional integral observer design for actuator fault estimation," in 16th International Mini Conference on Vehicle System Dynamics, Identification and Anomalies, VSDIA 2018, 2018.

[11] — - "Robust $\mathscr{H}_{\infty}$ proportional-integral observer for fault diagnosis: Application to vehicle suspension," IFAC-PapersOnLine, vol. 51, no. 24, pp. 536-543, 2018.

[12] S. Boyd, L. El Ghaoui, E. Feron, and V. Balakrishnan, Linear matrix inequalities in system and control theory. SIAM, 1994.

[13] Y. Wang, L. Xie, and C. E. de Souza, "Robust control of a class of uncertain nonlinear systems," Systems \& Control Letters, vol. 19, no. 2, pp. 139-149, 1992.

[14] D. W. Kammler, A first course in Fourier analysis. Cambridge University Press, 2007.

[15] W. S. Levine, The control handbook: Control system fundamentals. CRC press, 2010.

[16] M.-H. Do, D. Koenig, and D. Theilliol, "An integrated design for robust actuator fault accommodation based on $\mathscr{H}_{\infty}$ proportionalintegral observer," in 2018 IEEE Conference on Decision and Control (CDC). IEEE, 2018, pp. 6346-6352.

[17] J. Lofberg, "Yalmip: A toolbox for modeling and optimization in matlab," in Computer Aided Control Systems Design, 2004 IEEE International Symposium on. IEEE, 2004, pp. 284-289.
[18] J. F. Sturm, "Using sedumi 1.02, a matlab toolbox for optimization over symmetric cones," Optimization methods and software, vol. 11, no. 1-4, pp. 625-653, 1999.

[19] B. D. Anderson and J. B. Moore, Optimal control: linear quadratic methods. Courier Corporation, 2007.

[20] S. M. Savaresi, C. Poussot-Vassal, C. Spelta, O. Sename, and L. Dugard, Semi-active suspension control design for vehicles. Elsevier, 2010. 